\title{
RITUAL, RISCO E ARTE CIRCENSE: o homem em situações-limite
}

\author{
Luiz Guilherme Veiga de Almeida
}

Curso: Doutorado em Sociologia

Data de defesa da tese: 19 de março de 2004

Orientador: Prof. Dr. João Gabriel L. C. Teixeira

\section{Resumo}

O presente trabalho tem como tema a produção social de processos sensoriais. O pressuposto inicial é que as sociedades produzem espontaneamente diversas formas de relacionamento do homem com os sentidos, e que a compreensão da diversidade das experiências sensoriais é um caminho original para se compreender a natureza da estrutura social.

O tema se insere no campo dos estudos da performance, principalmente porque o conceito de performance envolve dois aspectos expressivos básicos das sociedades: o ritual e o espetáculo. Porém essas duas realizações tendem a ser compreendidas, do ponto de vista da performance, como eventos espetaculares e não como processos sensoriais. Assim, ao longo do trabalho, foi necessário realizar uma genealogia da noção de espetáculo para se entender a abrangência e, principalmente, os limites dessa noção.

As conclusões são basicamente duas: em primeiro lugar se desenvolveu um arcabouço conceitual capaz de descrever o ritual e o espetáculo como eventos sensoriais complexos, esse arcabouço está centrado no conceito de redoma sensorial. A partir desse conceito se estabeleceu que toda sociedade produz duas formas básicas de realização sensorial: uma ordinária e outra extraordinária. A segunda conclusão diz respeito ao estudo das experiências sensoriais extraordinárias e da importância dessas experiências na constituição 
do que se chamou de comunidades sensoriais, ou seja, grupos de indivíduos que estão unidos pelas experiências sensoriais que compartilham. Essa segunda parte envolveu uma pesquisa de campo na Escola Nacional de Circo, onde o pesquisador ingressou como aluno a fim de compreender o sentido e a pertinência do que se pode chamar de comunhão sensorial.

A conclusão final é que as experiências sensoriais extraordinárias são performances socialmente produzidos para gerar a própria coesão da sociedade. Isso ocorre através da exposição dos indivíduos a situações-limite envolvendo, normalmente, a presença do risco físico.

Palavras-chave: arte, ritual, performance, circo. 